\title{
Discrimination of snipefish Macroramphosus species and boarfish Capros aper morphotypes through multivariate analysis of body shape
}

Received: 1 November 2004/ Revised: 28 July 2005 / Accepted: 29 July 2005/Published online: 6 October 2005

(C) Springer-Verlag and AWI 2005

\begin{abstract}
The existence of two species of the genus Macroramphosus Lacepède 1803, has been discussed based on morphometric characters, diet composition and depth distribution. Another species, the boarfish Capros aper (Linnaeus 1758), caugth along the Portuguese coast, shows two different morphotypes, one type with smaller eyes and a deeper body than the other, occurring with intermediate forms. In both snipefish and boarfish no sexual dimorphism was found with respect to shape and length relationships. However, females in both genera were on average bigger than males. A multidimensional scaling analysis was performed using Procrustes distances, in order to check if shape geometry was effective in distinguishing the species of snipefish as well as the morphotypes of boarfish. A multivariate discriminant analysis using morphometric characters of snipefish and boarfish was carried out to validate the visual criteria for a distinction of species and morphotypes, respectively. Morphometric characters revealed a great discriminatory power to distinguish morphotypes. Both snipefish and boarfish are very abundant in Portuguese waters, showing two well-defined morphologies and intermediate forms. This study suggests that there may be two different species in each genus and that further studies on these fish should be carried out to investigate if there is reproductive isolation between the morphotypes of boarfish and to validate the species of snipefish.
\end{abstract}

Communicated by H.-D. Franke

M. Lopes $(\varangle) \cdot$ A. G. Murta

Instituto Nacional de Investigação Agrária e das Pescas

(INIAP/IPIMAR), Avenida de Brasília,

1449-006 Lisboa, Portugal

E-mail: mlopes@ipimar.pt

Tel.: + 351213027000

Fax: +351213015948

H. N. Cabral

Instituto de Oceanografia, Faculdade de Ciências da Universidade de Lisboa, Campo Grande, 1749-016 Lisboa, Portugal
Keywords Morphometrics - Capros aper.

Macroramphosus

\section{Introduction}

Two species of the genus Macroramphosus Lacepède 1803, have been described: longspine snipefish Macroramphosus. scolopax (Linnaeus 1758) and slender snipefish Macroramphosus gracilis (Lowe 1839). The former has a relatively shorter snout, deeper body, bigger eyes and a dorsal spine longer and closer to the tail fin than the latter (Albuquerque 1956; Fig. 1); it is referred to the whole Mediterranean Sea, Atlantic, Indian and Pacific Oceans, being distributed mainly in temperate latitudes between $20^{\circ}$ and $40^{\circ} \mathrm{N}$ (Ehrich 1986). $M$. gracilis was first described to Madeira Island and then to the Indo-Pacific, Eastern Central Pacific and Western Central Atlantic (Robins and Ray 1986).

Lo Bianco (1909, in D'Ancona 1933) was the first author who refuted the separation of those two species. He reported an experiment where small $M$. gracilis with $20 \mathrm{~mm}$ when grown up to $75 \mathrm{~mm}$ of total length, acquired a body morphology typical of $M$. scolopax. Based on these results D'Ancona (1933) concluded that $M$. scolopax and M. gracilis in the Mediterranean belong to the same species, the latter being a juvenile of the former. Also Ehrich (1976) considered M. gracilis as a juvenile of M. scolopax, based mainly on the existence of intermediate forms. However, several studies on morphometrics, growth and feeding ecology of snipefish carried out in different areas support the distinction between M. gracilis and M. scolopax (Brêthes 1979 for the Moroccan coast; Clarke 1984 for the southeast Australia; Assis 1993 and Borges 2000 for the Portuguese coast; Kuranaga and Sasaki 2000 and Miyazaky et al. 2004 for Japan; Matthiessen et al. 2003 and Matthiessen and Fock 2004 for the Great Meteor seamount).

Another species, the boarfish Capros aper (Linnaeus 1758), is common in North Atlantic waters and abundantly caught along the Portuguese coast. Recently, we 
Fig. 1 The two species of the genus Macroramphosus, Lacepède, 1803. a M. gracilis, b M. scolopax
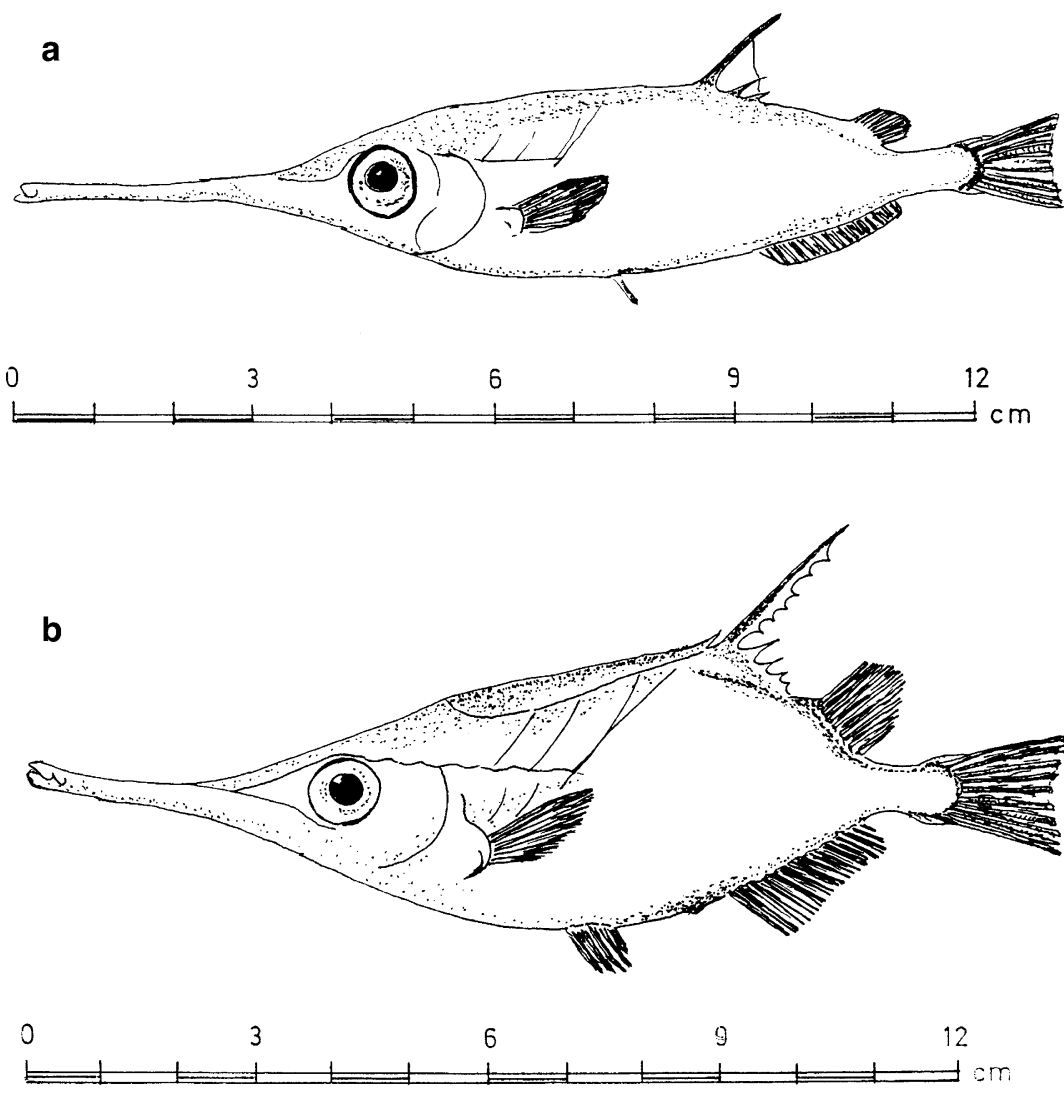

noticed that the individuals of this species can be classified into two distinct morphological types and individuals with intermediate characteristics. One of these types has smaller eyes, a deeper body and a more concave supra-orbital margin than the other (Fig. 2). This observation led to the hypothesis that the current systematic classification of boarfish may be mixing different species.

Morphometrics is a very useful tool in systematics, describing populational structures, identifying fish stocks and providing knowledge on the degree of intraspecific variation. The analysis of morphometric characteristics is used in this study to validate in a quantitative way the criteria used to distinguish snipefish species and boarfish morphotypes and to check whether the magnitude of the differences between the snipefish species is comparable to that between boarfish morphotypes. Given that the distinction of two species of Macroramphosus only on morphological evidence is valid, a similar degree of morphological differences between morphotypes of Capros would suggest the existence of two different species in these genus, too.

\section{Methods}

A total of 148 individuals of both species of snipefish and 145 individuals of boarfish were randomly sampled by bottom-trawl along the Portuguese coast (Fig. 3), between July 2002 and February 2003, and preserved frozen at $-20^{\circ} \mathrm{C}$. In the laboratory, specimens were classified according to snipefish species and boarfish morphotypes, and in both cases a third group of fish with intermediate shape characteristics was considered. Standard length was measured to the nearest $1 \mathrm{~mm}$ and sex was identified macroscopically for boarfish and histologically for snipefish, given the difficulty in determining sex in the latter. The length distributions of the samples are shown in Fig. 4.

Chi-square tests of $2 \times 2$ contingency tables (Zar 1996) were performed to check if there was independence between shape types and sex (in which case a separate analysis should be done for each sex), and between sex and length class. Length classes were defined as $\leq 115$ and $\geq 130 \mathrm{~mm}$ for snipefish and $\leq 95$ and $\geq 100 \mathrm{~mm}$ for boarfish. In these tests, individuals with shape characteristics considered as intermediate were not included.

To define the outline of the fish body, 13 landmarks were selected for snipefish and 11 for boarfish (Fig. 5). The fish were digitised with a scanner to avoid optical distortions, and the coordinates of each landmark were recorded with an image analysis software. The distances between landmarks were corrected to remove the size effect (Strauss 1985) using the method described by Ihssen et al. (1981):

$M_{c}=M(\overline{T L} / T L)^{b}$ 

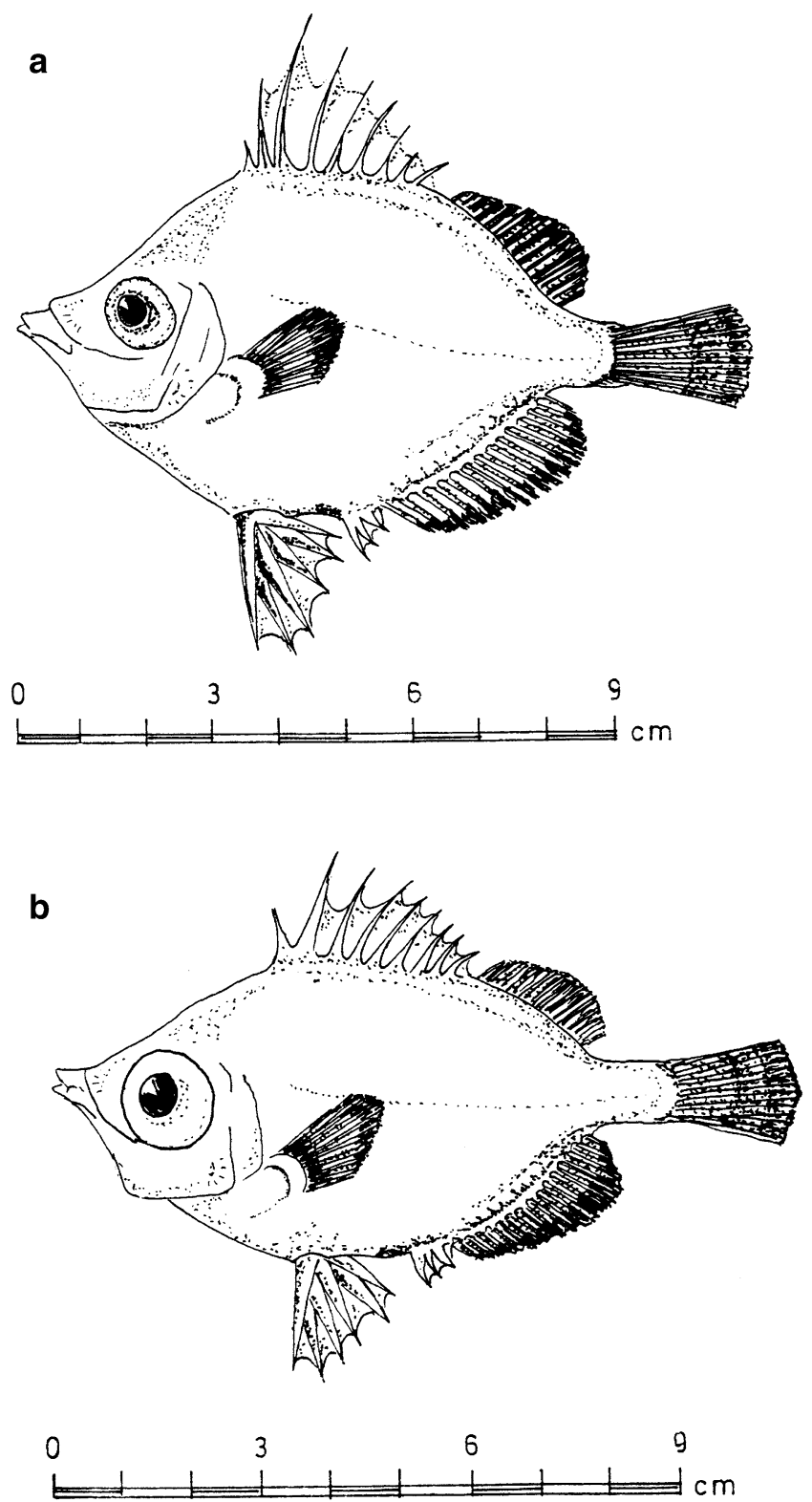

Fig. 2 The two morphotypes of the genus Capros, Lacepède, 1802. a Deeper type, $\mathbf{b}$ slender type

where $M_{c}$ is the size-corrected distance, $M$ the original measurement, $T L$ a reference length, $\overline{T L}$ the average reference length in the sample, and $b$ the slope of the geometric mean regression (Ricker 1973) on the logarithms of $M$ and $T L$. For snipefish the reference length adopted was the distance between landmarks 1 and 8, while for boarfish it was the distance between landmarks 1 and 7.

To investigate the morphological differences within each genus, the two-dimensional configurations of all individuals, given by their landmarks coordinates, were centered at the origin and scaled to the same size. Then, a least-squares Procrustes method (Rohlf 1990) was applied and a mean configuration was calculated for each morphotype. A reference individual was then

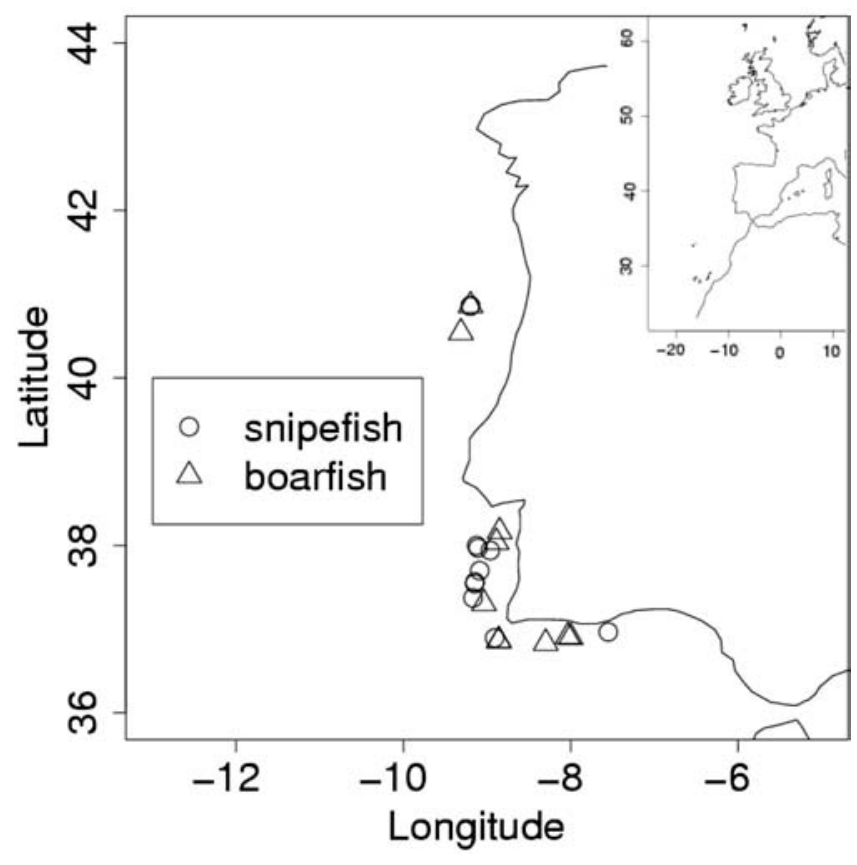

Fig. 3 Map showing the location of the sampling stations

chosen for snipefish and another for boarfish, and a Procrustes distance was calculated between each individual and the reference one. A multidimensional scaling (MDS) analysis was performed using the Procrustes distances in order to visually verify the aggregation of the individuals of the same type.

The visual criteria used to classify morphological species of snipefish (Albuquerque 1956) and morphotypes of boarfish correspond roughly to the distances between landmarks listed in Table 1. Multivariate discriminant analyses (Johnson and Wichern 1992) were performed to evaluate the discriminant power of those criteria, using one half of the individuals of each genus to calculate the discriminant functions, and the other half to validate those functions. The results from this procedure can be considered as a measure of the degree of subjectivity involved in the visual identification of the species or morphotypes.

\section{Results}

The length distributions of the snipefish sample (Fig. 4) revealed similar length ranges for $M$. scolopax and M. gracilis, whereas within the genus Capros, the deeper type presented a wide length range, compared with slender and intermediate types. The Chi-squared tests showed that the morphotypes of both genera were independent of sex (snipefish: $P=0.51,1 d f$; boarfish: $P=0.20,1 d f)$. For this reason, males and females were not analysed separately. However, in both genera, sex was not independent of length class, with females being, on average, bigger than males (snipefish: $P=0,1 d f$; boarfish: $P=0.004,1 d f$ ). 

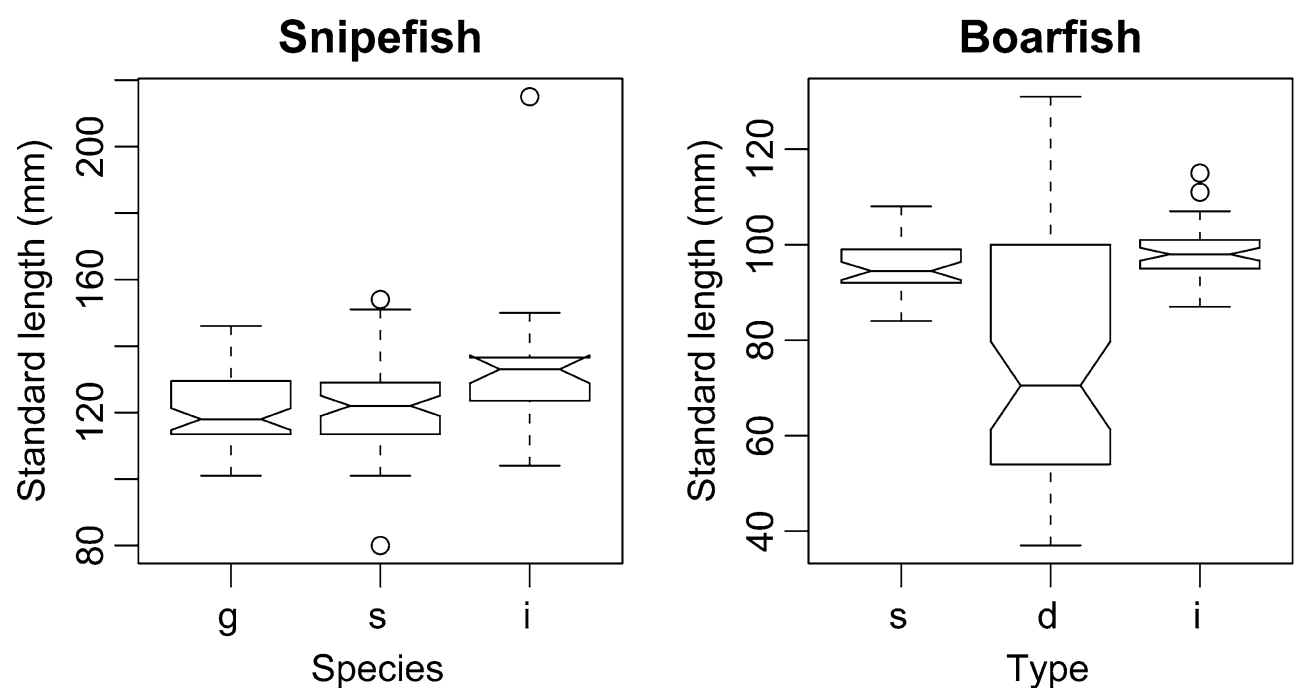

Fig. 4 Length distribution of snipefish species ( $s$. scolopax, g M. gracilis, $i$ individuals with intermediate characteristics) and boarfish morphotypes ( $s$ slender type, $d$ deeper type, $i$ intermediate type)

The mean configurations obtained with the Procrustes method revealed marked differences between the species of snipefish and also between the morphotypes of boarfish (Fig. 6). The differences between the species of snipefish are in agreement with those described in the literature (Albuquerque 1956; Fig. 1), with the exception that $M$. gracilis showed a higher mean of the eye diameter than M. scolopax, which is opposite to what is generally described (Albuquerque 1956). The differences between the morphotypes of boarfish were also in agreement with our description (Fig. 2).

In both genera, there was also clear separations between species and types, respectively, in the MDS ordination space (Fig. 7). M. scolopax and M. gracilis, as well as the deeper and slender of boarfish appeared well apart, while the intermediate individuals of snipefish appeared mixed with the $M$. gracilis, and the intermediate type of boarfish with the slender type.

The discrimination of morphological types based on the variables described in Table 1 resulted in a pattern similar to that obtained with the Procrustes approach (Fig. 8). The first linear discriminant expresses the difference between species and morphotypes. This first discriminant explains 96 and $100 \%$ of the variance between groups for snipefish and boarfish, respectively. The body height of snipefish was the variable with the highest correlation to the first discriminant axis, followed by the distance between the first dorsal and the tail fin, and by the dorsal spine length, while the eye diameter was more correlated to the second discriminant axis. For boarfish also, the body height showed the highest correlation to the first discriminant axis.

In the validation of the discriminant functions (Table 2) both $M$. scolopax and M. gracilis individuals formed well-defined groups, with only two individuals wrongly classified as intermediate. For boarfish, the most well-defined group was the slender type with $88 \%$ of the individuals correctly allocated, followed by the deeper type with $71 \%$. This results also revealed well defined groups for boarfish, since all misclassifications were related to the intermediate type with only one exception of an individual that we had classified as deeper and was allocated to the slender type.

\section{Discussion}

The results of the present paper suggest the existence of two distinct morphotypes of boarfish. It was also shown that the discrimination between these types, either by visual or morphometrical criteria, reveal a pattern that can be comparable to the distinction between snipefish species based on the same criteria. The existence of distinct forms of boarfish has never been reported before, which is an odd situation, given that this is a common species with a wide distribution (Heemstra 1986), and that thousands of boarfish individuals have been sampled along the Portuguese coast in the last 20 years during bottom-trawl surveys. This situation is probably due to the fact that boarfish in a certain haul belong mostly to the same morphotype, as observed during this study.

The length distribution of the snipefish sample (Fig. 4) revealed that the hypothesis of $M$. gracilis individuals being juveniles of $M$. scolopax must be rejected, since both species showed similar length ranges, as concluded by Borges (2000). The same can be seen for boarfish types, with the deeper type showing both the biggest and smallest individuals. Previous studies have reported differences between snipefish species regarding body shape (Clarke 1984; Assis 1993; Matthiessen et al. 2003), larval morphology (Kuranaga and Sasaki 2000; Miyazaki et al. 2004), diet composition (Clarke 1984; Matthiessen et al. 2003; Matthiessen and Fock 2004) and depth distribution (Villegas and Brêthes 1976; Clarke 1984). Some studies related the diet of the species 
Fig. 5 Landmarks defining the outline of the body of snipefish $\mathbf{a}$ and boarfish $\mathbf{b}$
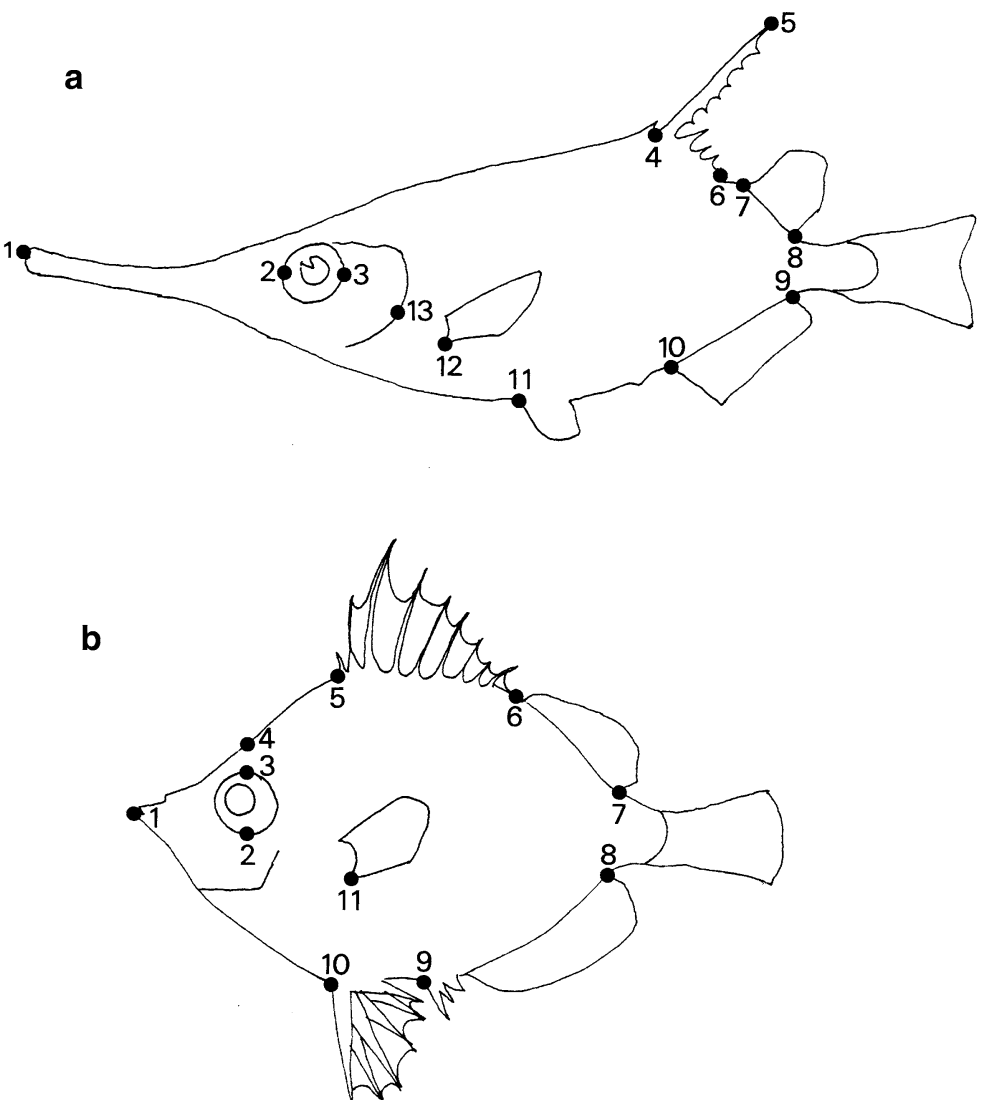

Table 1 Distances corresponding to the visual criteria used to classify specimens of snipefish and boarfish in the laboratory
Fig. 6 Mean configuration of snipefish species (s M. scolopax, $g$ M. gracilis, $i$ individuals with intermediate characteristics) and boarfish morphotypes $(s$ slender type, $d$ deeper type, $i$ intermediate type)

\begin{tabular}{|c|c|c|c|}
\hline \multicolumn{2}{|l|}{ Snipefish } & \multicolumn{2}{|l|}{ Boarfish } \\
\hline Distance & Landmark & Distance & Landmark \\
\hline Snout length & $1-2$ & Eye diameter & $2-3$ \\
\hline Eye diameter & $2-3$ & Body height & $5-10$ \\
\hline Dorsal spine length & $4-5$ & & \\
\hline Body height & $4-10$ & & \\
\hline $\begin{array}{l}\text { Between first dorsal } \\
\text { fin and tail fin }\end{array}$ & $6-8$ & & \\
\hline
\end{tabular}

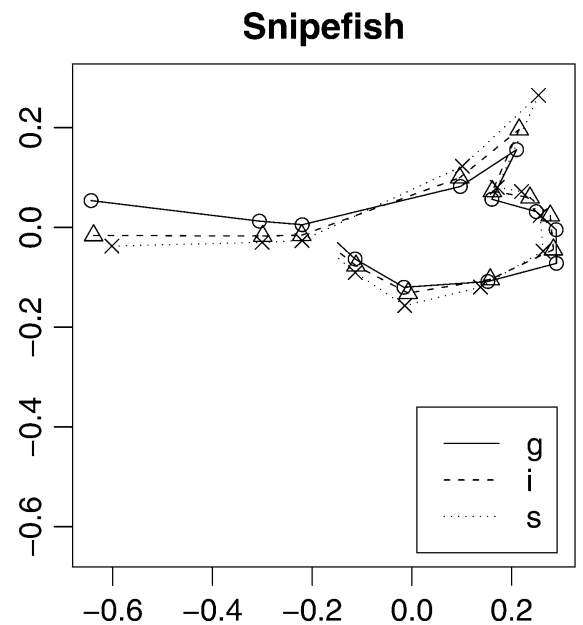

Boarfish

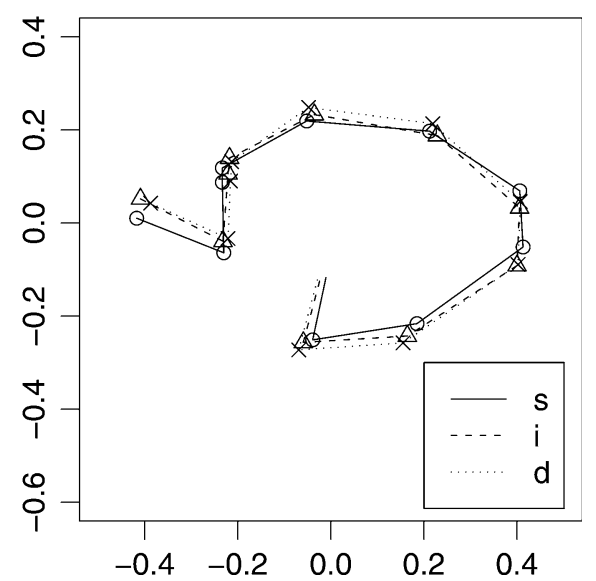


Fig. 7 Plot of MDS analysis of Procrustean distances of snipefish ( $s$ M. scolopax, $g$ M. gracilis, $i$ individuals with intermediate characteristics) and boarfish morphotypes $(s$ slender type, $d$ deeper type, $i$ intermediate type)
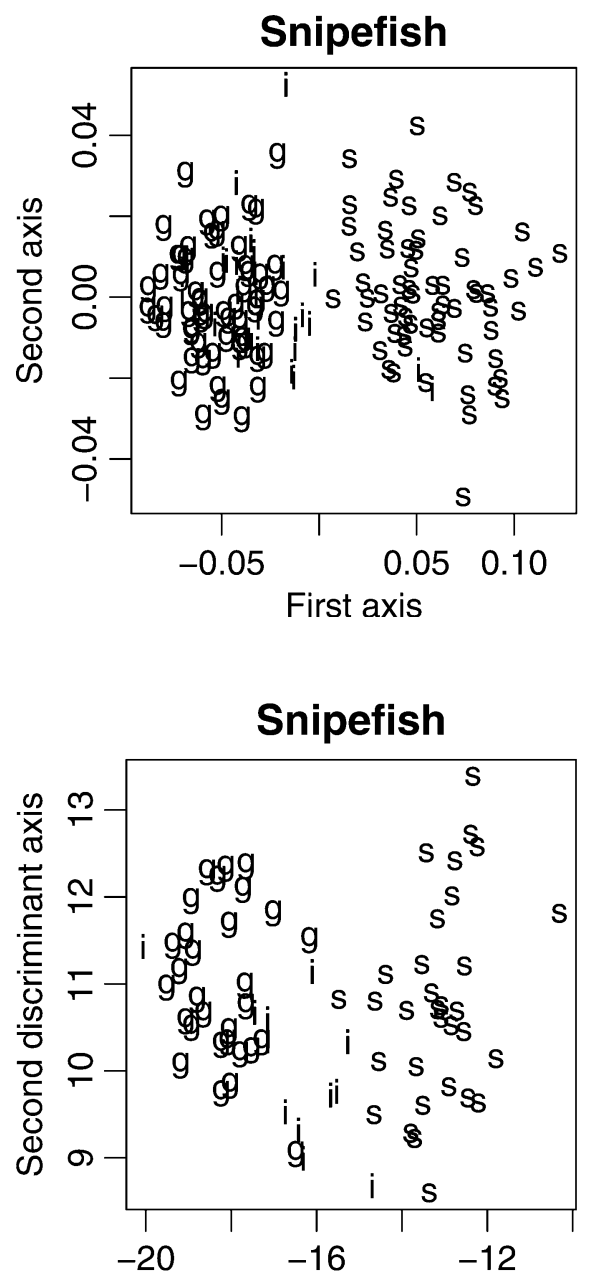

First discriminant axis

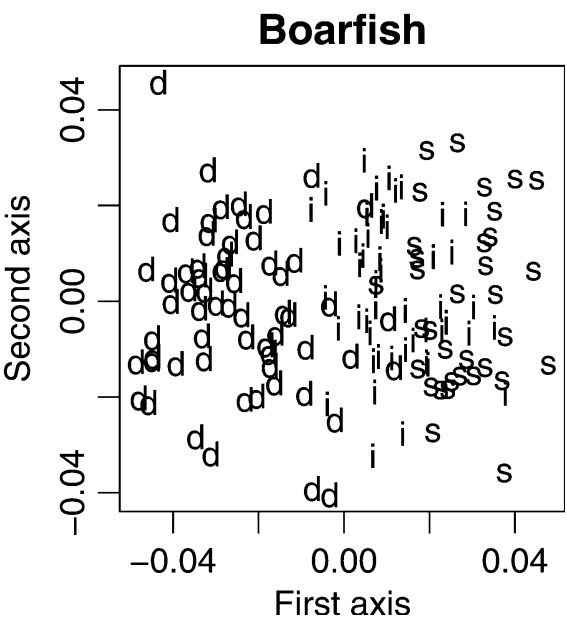

Boarfish

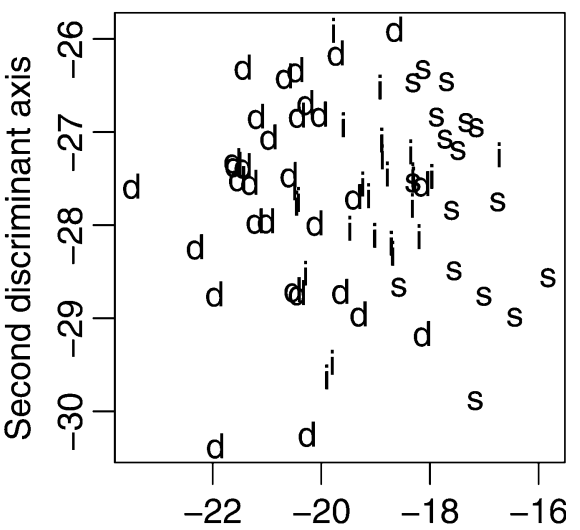

First discriminant axis

Table 2 Number and percentage of individuals allocated to each group, in the validation of the discriminant analysis for the morphometric data of snipefish and boarfish

\begin{tabular}{|c|c|c|c|c|}
\hline & M. scolopax & M. gracilis & Intermediate & Total \\
\hline \multicolumn{5}{|l|}{ Snipefish } \\
\hline M. scolopax & $30(94 \%)$ & $0(0 \%)$ & $2(6 \%)$ & 32 \\
\hline M. gracilis & $0(0 \%)$ & $28(93 \%)$ & $2(7 \%)$ & 30 \\
\hline \multirow[t]{2}{*}{ Intermediate } & $3(25 \%)$ & $3(25 \%)$ & $6(50 \%)$ & 12 \\
\hline & Slender & Deeper & Intermediate & Total \\
\hline \multicolumn{5}{|l|}{ Boarfish } \\
\hline Slender & $15(88 \%)$ & $0(0 \%)$ & $2(12 \%)$ & 17 \\
\hline Deeper & $1(3 \%)$ & $22(71 \%)$ & $8(26 \%)$ & 31 \\
\hline Intermediate & $5(21 \%)$ & $2(8 \%)$ & $17(71 \%)$ & 24 \\
\hline
\end{tabular}

with their bathymetrical distribution, as $M$. gracilis is a more pelagic species than M. scolopax (Clarke 1984; Matthiessen et al. 2003).

Body shape is determined by several factors such as the genetic pool, developmental constraints and responses to environmental conditions (Hanken and Wake 1991 in Valentin et al. 2002). Morphological changes often reflect environmental influences on embryonic and larval development and natural selec- tion on adults (Cock 1966). The typological species concept uses the degree of morphological differences as a criterion to separate species, as it is the case with the genus Macroramphosus. However, this concept has been rejected (Mayr and Ashlock 1991) in favour of the biological species concept which holds that two groups of individuals are separate species when they are reproductively isolated (Mayr and Ashlock 1991). 
The existence of individuals with intermediate morphological characters among both snipefish and boarfish raises some doubt that there is reproductive isolation. If snipefish species and boarfish morphotypes correspond to different species each, the intermediate forms may be hybrids or, if not, may have been subjected to particular environmental conditions at a certain stage in life. Assis (1993), by microscopic analysis of gonadal slices of snipefish individuals with intermediate characteristics, concluded that these individuals are fertile, although presenting lighter gonads and a lower gonadossomatic index (GSI) than M. scolopax and M. gracilis in a period close to the reproductive season. These findings disprove the hypothesis of the intermediate individuals being hybrids but do not give information about the validity of two different species and the origin of intermediate forms.

As in the case of snipefish, there is no genetic or other biological information on boarfish at the moment suggesting the existence of separate species. However, the situation in boarfish is strikingly similar to that in snipefish: individuals can be classified into two distinct morphotypes which seem to occur aggregated in separate shoals. Following the arguments which suggest the existence of two different species of snipefish on the basis of morphometric data, the existence of different species should also be considered provisionally for Capros aper until biological evidence is available to confirm or reject this hypothesis (Mayr and Ashlock 1991).

Acknowledgements The authors thank Mrs. Conceição Almeida for the scientific drawings. The first author was supported by a grant from PRODEP. This work was carried out within project "Pelágicos" funded by the Portuguese "Fundação para a Ciência e Tecnologia".

\section{References}

Albuquerque RM (1956) Peixes de Portugal e ilhas adjacentes. Chaves para a sua identificação. Portug Acta Biol (B) 5:525-528

Assis CA (1993) On the systematics of Macrorhamphosus scolopax (Linnaeus, 1758) and Macrorhamphosus gracilis (Lowe, 1839). II - Multivariate morphometric analysis. Arq Mus Bocage (new series) 22:383-402

Borges L (2000) Age and growth of the snipefish, Macroramphosus spp., in the Portuguese continental waters. J Mar Biol Assoc UK 80:147-153

Brêthes JC (1979) Contribution à l'étude des populations de Macrorhamphosus scolopax (L. 1758) et Macrorhamphosus gracilis (Lowe, 1839) des côtes Atlantiques Marocaines. Bull Inst Pêches Marit 24:1-62

Clarke TA (1984) Diet and morphological variation in snipefishes, presently recognized as Macrorhamphosus scolopax, from Southeast Australia: Evidence for two sexually dimorphic species. Copeia 3:595-608
Cock AG (1966) General aspects of metrical growth and form in animals. Q Rev Biol 41:131-190

D‘Ancona U (1933) Famiglia Macrorhamphosidae. In: D’Ancona U (ed) Fauna e flora del Golfo di Napoli. Monograf, Roma, pp 299-306

Ehrich S (1976) Zur Taxonomie, Oekologie und Wachstum von Macroramphosus scolopax (Linnaeus, 1758) (Pisces, Syngnathiformes) aus dem subtropischen Nordostatlantik. Ber Wiss Kommn Meeresforsch 24:251-266

Ehrich S (1986) Macroramphosidae. In: Whitehead PJP, Bauchot ML, Hureau JC, Nielsen J, Tortonese E (eds) Fishes of the North-eastern Atlantic and the Mediterranean II. UNESCO, Paris

Heemstra PC (1986) Caproidae. In: Smith M, Heemstra PC (eds) Smith's Sea Fishes. Springer, Berlin Heidelberg New York, pp 506-507

Ihssen PE, Evans DO, Christie WJ, Reckahn JA, DesJardine RL (1981) Life history, morphology, and electrophoretic characteristics of five allopatric stocks of late whitefish (Coregonus clupeaformis) in the Great Lakes region. Can J Fish Aquat Sci 38:1790-1807

Johnson RA, Wichern DW (ed) (1992) Applied multivariate statistical analysis, 3rd edn. Prentice-Hall, New Jersey

Kuranaga I, Sasaki K (2000) Larval development in a snipefish (Macroramphosus scolopax) from Japan with notes on eastern Pacific and Mediterranean Macroramphosus larvae (Gasterosteiformes, Macroramphosidae). Ichthyol Res 47:101-106

Matthiessen B, Fock HO (2004) A null model for the analysis of dietary overlap in Macroramphosus spp. at the Great Meteor Seamount (subtropical North-east Atlantic). Arch Fish Mar Res 51:294-304

Matthiessen B, Fock HO, Westernhagen Hv (2003) Evidence for two sympatric species of snipefishes Macroramphosus spp. (Syngnathiformes, Centriscidae) on Great Meteor Seamount. Helgoland Mar Res 57:63-72

Mayr E, Ashlock PD (1991) Principles of systematic zoology, 2nd edn. McGraw Hill, New York

Miyazaki E, Sasaki K, Mitani M, Uehara S (2004) The occurrence of two species of Macroramphosus (Gasterosteiformes: Macroramphosidae) in Japan: morphological and ecological observations on larvae, juveniles, and adults. Ichthyol Res $51: 256-262$

Ricker WE (1973) Linear regressions in fishery research. J Fish Res Board Can 30:409-434

Robins CR, Ray GC (1986) A field guide to Atlantic coast fishes of North America. Houghton Mifflin Company, Boston

Rohlf FJ (1990) Rotational fit (Procrustes) Methods. In: Rohlf FJ, Bookstein FL (eds) Proceedings of the Michigan Morphometrics Workshop. University of Michigan Museum of Zoology, Michigan, pp 227-236

Strauss RR (1985) Evolutionary allometry and variation in body form in the South American catfish genus Corydoras (Callichthydae). Syst Zool 34:381-396

Valentin A, Sévigni JM, Chanut JP (2002) Geometric morphometrics reveals body shape differences between sympatric redfish Sebastes mentella, Sebastes fasciatus and their hybrids in the Gulf of St Lawrence. J Fish Biol 60:857-871

Villegas L, Brêthes JC (1976) Distribution et abondance relative de la Becasse dans l'Atlantique Marocain. Trav Doc Dév Pêches Maroc 17:1-19

Zar JH (ed) (1996) Biostatistical analysis, 3rd edn. Prentice-Hall, New Jersey 